\title{
Effect of Telephone Counselling (Telenursing) on the Quality of Life of the Patients with Colostomy
}

\author{
Maryam Parchami Iraqi ${ }^{1}$, Zahra Ahmadi ${ }^{*}$ \\ 1. Department of Nursing, Community Health Education, Khatam Al-Anbia Hospital, Tehran University of Medical Sciences, Tehran, Iran. \\ 2. Department of Nursing, School of Nursing and Midwifery, Iran University of Medical Sciences, Tehran, Iran.
}

Citation: Parchami Iraqi, M, Ahmadi, Z 2016, 'Effect of Telephone Counselling (Telenursing) on the Quality of Life of the Patients with Colostomy', Journal of Client-Centered Nursing Care, vol. 2, no. 2, pp. 123-130. https://doi.org/10.32598/jccnc.2.2.123

Article info:

Received: 13 Jan. 2016

Accepted: 12 Apr. 2016
Keywords:

Colostomy, Telephone counselling, Quality of life

\begin{abstract}
A B S T RA C T
Background: The number of patients with colostomy is increasing every day. Caring of patients with colostomy after operation should be based on different aspects of their quality of life (QoL). This study was conducted to determine the effect of telephone counselling (telenursing) by nurses on the QoL of patients with permanent colostomy.

Methods: This research was a randomized clinical trial study with the control group. It was conducted on the patients referring to Iranian Ostomy Society, Tehran, Iran. At first, a total of 70 patients with permanent colostomy were selected by convenience sampling method and then randomly assigned in the experimental group (with telephone counselling) and control group. Patients in both groups followed training sessions as usual and participated in it. Data collection tool was City of Hope-quality of life-Ostomy questionnaire. QoL was measured at the beginning of the intervention and then 16 weeks later. Statistical data were analyzed using descriptive statistics, paired $t$ test, independent $t$ test, and analysis of covariance. Data analysis was performed by SPSS version 22 .
\end{abstract}

Results: After telephone counseling, significant differences were observed between two groups with regard to physical $(\mathrm{P}=0.007)$, mental $(\mathrm{P}<0.001)$, and social $(\mathrm{P}<0.001)$ aspects of patients' QoL. Regarding the spiritual aspect of QoL, no significant difference was found between two groups $(\mathrm{P}=0.111)$ after telephone counselling. All in all and compared with the control group, telephone counselling was significantly effective on the patients' QoL $(\mathrm{P}<0.001)$.

Conclusion: Based on the results, telephone counselling was effective on physical, mental, and social aspects of patients' QoL and can be used to improve the QoL and health of the patients with colostomy. In this regard, nurses as the main members of the health staff can use telephone counselling program to help their patients.

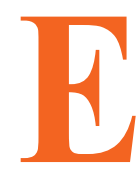

\section{Introduction}

very year, the number of patients with colostomy rises because of the prevalence of colorectal tumors. Every day many patients with this cancer are subject to make important decisions whether to lose their normal bowel movements and undergo ostomy operation permanently or temporarily (Nobahar

\section{* Corresponding Author:}

Zahra Ahmadi, MSc.

Address: Department of Community Health Nursing, School of Nursing \& Midwifery, Iran University of Medical Sciences, Rashid Yasemi St., Vali-Asr Ave, Tehran, Iran Tel: +98 (919) 3230471

E-mail: ahmadizahra385@yahoo.com 
2002). Injuries, congenital diseases of the intestine, and complications related to abdominal surgery may lead to colostomy (Duchesne et al. 2002). During this operation which is performed on all ages from infancy to old age, defecation route is diverted to the outside through a central abdominal incision (Ontario 2009). In Iran, the number of ostomists is about 30000 ; of them $70 \%$ have colostomy, $20 \%$ ileostomy, and 10\% urostomy. Over 2000 patients are members of Iranian Ostomy Society. Of these patients, about $10 \%$ have temporary problems and the rest have permanent problems who undergo operation each year due to different reasons (Iranian Ostomy Society 2012).

Given that life expectancy of cancer patients barely reaches 5 years and in some cases, it is even shorter (Pisani et al. 2002), ostomy is sometimes performed for patient's survival and sometimes for improving the patient's quality of life (QoL). In both cases, the patient is faced with too much stress. Losing bowel control, normal body form, and confidence in socializing; developing family problems; incurring costs of equipment needed, suffering from psychological problems caused by the disease and ostomy acceptance are factors creating psychological crisis (Care of Ostomy 2007;Burch 2005; Braun 2009). QoL is a multidimensional concept, including physical, mental, spiritual, and social aspects. This concept is influenced by different factors such as physical environment, socioeconomic status, culture, events, and diseases (Wu et al. 2007).

Colostomy causes physical, psychological, and social discomfort, due to changes in the body (Burch 2005). With regard to social aspect, due to sudden changes in the body, the mental image of the patient for contributing in the society and his or her efficiency change, which makes the patient's QoL undesirable. Regarding the physical and mental aspects, patients with ostomy have concerns about the lack of sphincter control, sound of bowel movement, changes in gas expel, discomfort from presence in the community due to an unpleasant odor, worry about filling colostomy bag, damage to the skin around the colostomy as well as psychological changes related to impaired mental image that would affect their QoL (Aghabarari et al. 2006; Smith et al. 2007).

Furthermore, because of religious beliefs such as impurity and purity, patients are not interested in taking care of stoma. This disinterest makes some problems for them (Grinspun 2009). Fear of ostomy and sexual function are the issues which affect the patients more than other problems (Charua-Guindic et al. 2011; Mistiaen \& Poot, 2006). Previous studies were usually conducted to investigate disease recurrence or mortality and con- cerned less about patient's follow-up after discharge to assess his or her training needs and provide emotional and social support for him or her. The patient's survival after operation should not be the only reason for patient's follow-up (Beaver et al. 2010). Counselling with these patients should be continued to identify their physical and psychological needs (Black 2005).

Mobile communication has created opportunities, which extended the patient's care from mere clinics and hospitals to the patient's daily life at homes (Peck 2005, Black 2005). Telenursing, by definition, includes application of the nursing process in providing care to a patient or a group of patients by telecommunication. Using phone, nurse investigates needs of the patient, and if necessary, refers him or her to appropriate resources. As follows, services are placed at clients' disposal based on their needs. Research in telephone counselling has shown that this method reduces patient's stress, anxiety, and depression and increases patient's self-esteem and compliance (Allen-Davis et al. 2002 ). Because the majority of clients have access to the phone, even in remote areas, using this method not only reduces the number of patient's referrals to hospitals and the health care centers but also saves time and costs imposed on the patient and health system (Braun et al. 2009).

Moreover, this approach improves the relationship between patient and care providers by removing space and time barriers and facilitates access to caring (Zakerimoghadam, 2008). Actually, remote education and counseling by telenursing is referred to the use of telecommunication technology in nursing to improve the quality of care for patients. It involves using electromagnetic channels to transmit voice, data, and video signals (International Nurses Concil 2006). Today, by using telenursing caring methods, nurses are able to take measures such as monitoring patient, educating, consulting, following up, collecting data, nursing interventions, managing pain, and supporting patient (Peck 2005). Studies show that telephone counselling of nurse with the patient after discharge is a useful program (besides the treatment) which can be considered in patients with cancer (Beaver et al. 1999; Beaver et al. 2011). Patient's follow-up care through telephone is a helpful way which not only supports the patient after discharge but also helps the nurse continue patient's care and education (Zhang et al. 2012)

Besides, patients are often very busy and cannot participate in training and consulting programs or coordinate their work schedule to attend formal training and advisory programs (Azar \& Gabbay 2009, Sacco 2004). In 2010, Sadeghi et al. investigated the effect of telephone 
follow-up by nurses on glycosylated hemoglobin level of diabetic patients. They found that this method was effective in reducing glycosylated hemoglobin in patients with diabetes (Sadeghi 2010).

Nurses who have basically a training and advisory mission, play an important role in providing information and essential advice for caring patients with colostomy. To support these patients, Society for the Protection of Ostomy Patients has been established in most developed countries (Beaver et al. 2010; Karadag et al. 2003). Iranian Ostomy Society is a charity institute which was established in 2001. At the moment, its members are more than 2000 people. Among the functions of this society, we can mention training and advice sessions about ostomy to improve the patients' QoL (Iranian Ostomy Society 2012). Education and counselling by nurses to colostomy patients helps them be compatible with ostomy in less than two to three weeks and regain their independence (Black 2005). The current study was conducted to determine the effect of telephone counselling (telenursing) on the QoL of patients with colostomy.

\section{Materials \& Methods}

This study was a randomized clinical trial with a control group. The study sample comprised 70 patients with permanent colostomy referring to Iranian Ostomy Society (in 2013) who referred to this center in less than a month after discharge from the hospital. The samples were selected by convenience sampling method. Inclusion criteria comprised being 18 to 80 years old, having full consciousness and access to phone at home, not having speech and hearing problems and not undergoing operation simultaneous with colostomy. Exclusion criterion was the patient's unwillingness to continue the study.

Samples were divided into experimental and control groups and 35 participants were present in each group. Data collection was conducted through a questionnaire on ostomy patients' QoL. The questionnaire consisted of 55 questions in which the first part contains 12 questions about demographic characteristics and disease. The second part includes 43 questions about the effects of ostomy on the QoL. The questions examined the physical (questions 1-11), mental (questions 12-24), social (questions 25-36), and spiritual (questions 37-43) aspects of QoL. Questions of this part are rated based on the Likerttype scale from 0 to 10 and are used in the calculation of mean score of QoL. In some questions, higher scores reflect better QoL and in other questions, lower rating indicates better QoL. In questions with negative bias (ques- tions $1,12,15,18,19,22,30,32,34,37)$, score 10 represents the poorest QoL and score 0 , the best QoL. When calculating the score of each question, reverse changes were initially applied.

Grant et al. (2004) in a study revised this questionnaire and determined its validity and reliability. Its internal validity was determined in Naseh et al. study (2010) and the value of Cronbach $\alpha$ coefficient for QoL instrument was found to be 0.95 and the correlation coefficient for physical, mental, social, and spiritual aspects of QoL were obtained as $0.82,0.88,0.83$, and 0.78 , respectively. This questionnaire was given to patients in both groups before and 3 months after the intervention. During the presentation of the questionnaire, the researcher read questions for low-literate or illiterate patients and their answers were written down as they were.

Both experimental and control groups received common training in the Society individually. In this intervention, the researcher followed up and advised the study group for a period of 3 months by telephone. The experimental group were consulted by phone, two phone calls per week in the first month, then one phone call per week in the second and third months of the intervention.

Time dedicated for each phone call was 15 to 30 minutes. Because of the location and the chronic nature of the disease, the main focus of counselling was on patients' knowledge and skills on how to replace and install colostomy bags, how often replace the bag, caring the skin around the stoma, bathing and washing of ostomy, nutrition, how to treat diarrhea or constipation, travelling with colostomy, sexual intercourse, use of the food or substance that can cause bad odor of feces, referring patient to healthcare centers to reduce the economic problems that the disease imposed on the person, and finally about the presence of these patients in public. The participants were asked to provide the researcher with their suggestions and solutions regarding the best plan to improve their QoL. Control group only received common training which were provided individually in the Society and no intervention was performed in the form of telephone counselling for this group of patients.

To analyze the findings, the Chi-square and Fisher Exact tests (to compare nominal variables), independent $t$ test (to compare mean results of two groups found in pretest or posttest), paired $t$ test (comparing the mean results of one group on two occasions of pretest and posttest), and analysis of covariance (to compare the mean of posttest results in two groups of intervention and control with the effect size of pretest) were used at the significant 
Table 1. Mean scores of QoL and its aspects in patients with colostomy, experimental and control groups, before and after the intervention.

\begin{tabular}{|c|c|c|c|c|c|}
\hline \multirow{2}{*}{ Variable } & \multirow{2}{*}{ Group } & \multicolumn{2}{|c|}{ Pretest } & \multicolumn{2}{|c|}{ Posttest } \\
\hline & & Mean & SD & Mean & SD \\
\hline \multirow{2}{*}{ Physical aspect } & Experimental & 40.94 & 8.22 & 58.71 & 5.52 \\
\hline & Control & 42.11 & 6.72 & 55.48 & 7.5 \\
\hline \multirow{2}{*}{ Mental aspect } & Experimental & 46.97 & 10.78 & 57.20 & 8.93 \\
\hline & Control & 44.62 & 7.79 & 48.80 & 7.11 \\
\hline \multirow{2}{*}{ Social aspect } & Experimental & 54.17 & 10.43 & 62.45 & 7.52 \\
\hline & Control & 59.54 & 9.79 & 60.68 & 6.24 \\
\hline \multirow{2}{*}{ Spiritual aspect } & Experimental & 26.85 & 7.30 & 33.54 & 5.01 \\
\hline & Control & 26.68 & 5.20 & 31.74 & 4.23 \\
\hline \multirow{2}{*}{ General QoL score } & Experimental & 168.94 & 23.08 & 211.05 & 17.92 \\
\hline & Control & 172.97 & 16.87 & 196.71 & 15.74 \\
\hline
\end{tabular}

Client-Centered Nursing Care

level of $\mathrm{P}<0.05$. All calculations were performed using SPSS version 22

\section{Results}

The age range of the subjects was 24-78 years. Both experimental and control groups were homogenous regarding age and gender. In the experimental group, the mean age was 52.60 years and for the control group 50.86 years. In the experimental group, $60 \%$ of the participants were women and $40 \%$ were men. In the control group, $65.7 \%$ were women and $43.3 \%$ were men. In Table 1, the mean and standard deviation of patients' QoL score and its aspects are provided in two occasions of pretest and posttest. Table 2 shows that after statistically controlling differences in mean scores of the spiritual aspect of QoL of groups in the pretest, phone counselling had no significant effect on the spiritual aspect of QoL scores in posttest $(\mathrm{P}=0.111)$, i.e. the spiritual aspect of QoL showed no difference between experimental and control groups after telephone counselling.

According to Table 2, telephone counselling affected QoL and its three aspects; physical, mental, and social. After statistically controlling for differences in the mean scores of the physical aspect of QoL in the pretest,

Table 2. Results of analysis of covariance to compare QoL in study patients.

\begin{tabular}{|c|c|c|c|c|c|c|c|}
\hline Variable & Resource & $\begin{array}{l}\text { Sum of } \\
\text { squares }\end{array}$ & $\begin{array}{l}\text { Degree of } \\
\text { freedom }\end{array}$ & $\begin{array}{c}\text { Mean of } \\
\text { squares }\end{array}$ & F statistics & $\begin{array}{l}\text { Probability } \\
\text { value }\end{array}$ & Effect size \\
\hline \multirow{3}{*}{ Physical aspect } & Pretest & 678.40 & 1 & 678.40 & 22.15 & $<0.001$ & 0.249 \\
\hline & Group & 240.81 & 1 & 240.81 & 7.86 & $=0.007$ & 0.105 \\
\hline & Error & 2051.47 & 67 & 30.61 & & & \\
\hline \multirow{3}{*}{ Mental aspect } & Pretest & 558.80 & 1 & 558.80 & 9.66 & $=0.003$ & 0.126 \\
\hline & Group & 1017.67 & 1 & 1017.67 & 17.59 & $<0.001$ & 0.208 \\
\hline & Error & 3874.39 & 67 & 57.82 & & & \\
\hline \multirow{3}{*}{ Social aspect } & Pretest & 1634.01 & 1 & 1634.01 & 67.73 & $<0.001$ & 0.503 \\
\hline & Group & 312.08 & 1 & 312.08 & 12.93 & $<0.001$ & 0.162 \\
\hline & Error & 1616.22 & 67 & 24.12 & & & \\
\hline \multirow{3}{*}{ Spiritual aspect } & Pretest & 46.62 & 1 & 42.62 & 2.20 & $=0.142$ & 0.032 \\
\hline & Group & 55.28 & 1 & 55.28 & 2.61 & $=0.111$ & 0.038 \\
\hline & Error & 1416.74 & 67 & 21.14 & & & \\
\hline \multirow{3}{*}{ General QoL score } & Pretest & 3333.74 & 1 & 3333.74 & 13.93 & $<0.001$ & 0.172 \\
\hline & Group & 4290.47 & 1 & 4290.47 & 17.93 & $<0.001$ & 0.211 \\
\hline & Error & 16029.28 & 67 & 239.24 & & & \\
\hline
\end{tabular}


telenursing showed a significant effect on the physical aspect of QoL scores $(\mathrm{P}=0.007)$. Given the effect size, we can say that $10.5 \%$ of change in QoL in the posttest was due to intervention, i.e., physical aspect of QoL was different in experimental and control groups after telephone counseling. The increase in the mean scores of physical aspect of QoL in the experimental group has been significantly more than the control group. Also, after statistically controlling for differences in the mean scores of the mental aspect of QoL of groups in the pretest, intervention (telephone counselling) had a significant effect on mental aspect of QoL scores in the posttest $(\mathrm{P}<0.001)$. Given the effect size, $20.8 \%$ of change in the mental aspect of QoL in the posttest was due to intervention, i.e., the mental aspect of QoL was different in experimental and control groups after telephone counselling. The increase in the mean scores of the mental aspect of QoL in the experimental group was significantly more than that in the control group.

After statistically controlling for differences in the social aspect of QoL scores at pretest, intervention (telephone counselling) showed a significant effect on the social aspect of QoL scores in the posttest $(\mathrm{P}<0.001)$. Given the effect size, $16.2 \%$ of changes in the social aspect of QoL in the posttest was explained by intervention, i.e., the social aspect of QoL was different in experimental and control groups after telephone counselling. Furthermore, the increase in the mean scores of the social aspects of QoL in the experimental group was significantly more than that in the control group. Likewise, after statistically controlling for differences in mean scores of general QoL of groups in the pretest, telenursing had a significant effect on the general QoL scores $(\mathrm{P}=0.007)$. Given the effect size, $21.1 \%$ of change in QoL in the posttest was due to intervention, i.e., general QoL was different in experimental and control groups after telephone counselling. The increase in the mean scores of general QoL in the experimental group has been significantly more than that in the control group.

\section{Discussion}

In this study, there was a statistically significant difference in the mean values of physical aspect of QoL in pretest and posttest of the experimental group $(\mathrm{P}<0.001)$. Results of the current study is consistent with the results of Sadeghi et al. (2010) (Sadeghi et al. 2010), Nesar et al. (2008) (Zakerimoghadam et al. 2008), and Ilknur et al. (2010) studies (Cinar et al. 2010). These studies showed that after several weeks of telephone follow-up by nurses in diabetic patients in the experimental group, their blood glucose, glycosylated hemoglobin, blood lip- ids, and adherence to diet showed statistically significant differences with the control group $(\mathrm{P}<0.05)$.

The study by Ali Akbari et al. (2008) (Ali Akbari et al. 2009) also showed that mean(SD) QoL score before intervention in two groups were 54.45(13.11) and 52.23(15.86), respectively $(\mathrm{P}<0.05)$. The mean scores of QoL in two groups had no significant difference before the intervention, but after conducting the study, the mean(SD) scores of the experimental and control groups were 76.27(14.42) and 54.11(14.86) $(\mathrm{P}<0.001)$. Holst et al. (2006) conducted a study to determine the effect of telephone follow-up on self-care of patients with heart failure.

They showed that intervention had no impact on patients' physical aspect of QoL and researchers stated that this may be due to the low number of phone calls or inadequate training that have been provided (Holst et al. 2007). The results of Kimman et al. (2011) study showed that telephone follow-up by nurses after 12 months of treatment did not improve physical aspect and according to the researcher it was due to outpatient follow-up of patients along with telephone follow-up. Also, psychological factors of patients during telephone follow-up were mentioned as other factors contributing to this result.

In this study, there was no statistically significant difference between experimental and control groups, regarding mental aspect of $\mathrm{QoL}$ in the pretest $(\mathrm{P}=0.301)$. Results of Zheng et al. (2013) were consistent with the results of this study. However, our finding are in contrast with the findings of Beaver et al. (2010) and Richburg et al. (2007) studies where they emphasized that telephone counselling must focus on providing patients with more information regarding their diseases and ignored the psychological needs of the patients. If psychological problems and anxiety about the disease in these patients are ignored, it can lead to sensitivity of patients about their issues and socio-economic costs associated with repeated visits to clinics and consequently additional costs on the health system (Xu 2009).

The results of Zhang et al. (2013) study also showed that telephone follow-up had no effect on psychological aspect of the patients with colostomy and researchers mentioned that the reason can be related to culture issues or insufficient address to psychological problems of the patients by nurses (Zhang et al. 2012). Also in Ali Akbari et al. (2008) study,after the telephone intervention, QoL in the experimental group showed a significant improvement compared to the control group (Ali Akbari et al. 2009). Liu et al. (2005) suggested that patients in some 
cultures tended to share their psychological problems and emotional issues with their close family members and did not expect that nurses replace their close family members in providing psychological support to them (Liu et al. 2005).

Colostomy is a safe treatment for patients with intestinal disorders, however the psychological effects of stoma is high. Thus, counselling and educating patients with colostomy can improve their psychological compatibility (Smith et al. 2007). Patients who refused revealing their feelings, think that they should control themselves and should not upset the nurses or disturb them (Burch 2005).Meanwhile, most nurses focus on physical aspects of caring and forget mental issues (Liu et al. 2005). Therefore, if psychological support in this group of patients were done well, successful compliance of colostomy patients with their diseases would be more likely (Zheng et al. 2013). In investigation of women with breast cancer, Sammarco (2001) concluded that the degree of individual's belonging to a support network was a precious resource in psychological adjustment.

It seems that telephone follow-up of patients with colostomy immediately after hospital discharge greatly encouraged patients and gave them confidence to face with problems. This was also more effective in the psychological adjustment of patients who received this type of follow-up than patients who did not (Zhang et al. 2012). These findings are consistent with the findings of $\mathrm{Xu}$ (2009) study who believed that a clinical guide and tips to cope with stoma for patients with colostomy at home (after hospital discharge) was very effective in restoring their independence and reducing psychological stress (Xu 2009).

The difference between groups with regard to mean scores of the social aspect of QoL in the pretest, was significant after telephone counselling $(\mathrm{P}<0.001)$. These findings agree with Zheng et al. results (Zheng et al. 2013). Also according to the study by Sammarco et al. (2001), existence of support networks and membership of patients in support groups have a significant impact on social adjustment and improvement of the social aspect of the patient's QoL (Sammarco 2001).

In this study, it seems that interaction with nurse by phone and patient's support have been effective in patient's return to social life. This finding is consistent with the results of Pringle et al. (2001) study about the importance of returning patients to everyday life (Pringle \& Swan 2001). Keeping a normal life depicts patient's efforts to face the problem and in this regard the role of follow-up by the nurse is outstanding (Burch 2005). Communication with the nurse by phone and getting advice about problems of interaction with people, involvement in the community, and how to comply with colostomy in order to continue normal social life as well as guiding family members and close relatives of the patient to help him or her in social adjustment are important aspects of telephone follow-up of patients with colostomy by nurses (Zhang et al. 2012). This finding is also consistent with the results of ilknur et al. (2010) study about improving the QoL of patients regarding the social aspect after telephone follow-up (Cinar et al. 2010).

The difference in pretest QoL scores of spiritual aspect between groups had no significant effect on mean scores of the variable in the posttest after telephone counselling $(\mathrm{P}=0.111)$. This finding is consistent with the findings of Zheng et al. (2013). Religious patients have already had beliefs about colostomy (Zheng et al. 2013) and telephone follow-up has no effect on changing these beliefs (Beaver et al. 2010). Participants may also use unreal answers to questions related to the spiritual beliefs because of social and personal beliefs which is out of researcher's control (Pittman et al. 2009).

Research findings was in conflict with the results of Persson et al. (2004) study where separation of patients from religious communities and less participation in religious activities happened because of problems arising from the stoma such as odor, gas, low self-esteem, and depression (Persson et al. 2004). Zheng et al. (2013) also suggested that the ineffectiveness of telephone follow-up on the spiritual aspect of QoL in patients with colostomy could be due to the fact that nurses discuss these matters less with the patient during a telephone conversation and focus more on addressing the patient's physical and social problems (Zheng et al. 2013). Due to cultural and psychological issues of the patients, they should be asked to discuss religious issues and, if necessary, patients should be referred to the appropriate authorities (Yang et al. 2003).

In this study, we investigated the effect of telephone counselling by nurse on QoL of patients with colostomy. Because several factors affecting QoL, we have to use new, inexpensive, easily accessible, and practical methods to investigate the QoL in patients with colostomy and respond to their educational needs. In this regard, telephone counselling is an effective method. Counseling and education of patients with colostomy in various fields and establishment of associations supporting the patients effectively have a significant role in improving the patients' QoL. While the effectiveness of telephone counselling is less than face-to- 
face visits, it is still very useful and valuable in providing care in a short-time care interventions and when caring is turned from hospital-based to community-based and from the care-based to patient-based.

By using this technology, services are transferred to patient's home that is more comfortable. Promoting knowledge of nurses and using specialist enterostomal nurses, rise quality of patient's education. Furthermore, careful and regular planning before and after the operation are necessary for making appropriate decisions to provide useful and practical training with physical, mental, social, spiritual aspects of patients with colostomy. Community health nurses who basically have the mission of giving advice and education play an important role in achieving this goal and addressing the needs of patients with colostomy. Given the significant effect of telephone counselling by nurse on the QoL of patients with colostomy, it is recommended that this program be used at all general and specialized levels of healthcare system, due to its cheap, convenient and availability to all nurses, nursing educators, and students.

\section{Acknowledgments}

Finally, we appreciate the deputy of Tehran University of Medical Sciences, also the president and staff of Iranian Ostomy Center as well as all study patients who helped us patiently despite their illnesses.

\section{Conflict of Interest}

The authors declared no conflict of interest.

\section{References}

Agarwal, S \& Ehrlich, A 2010, 'Stoma dermatitis: prevalent but often overlooked', Dermatitis, vol.21, no.3, pp.138-47.

Aghabarari, M, Ahmadi, F, Mohammadi, E, Hajizadeh, E \& Farahani, A 2006, '[Physical, spiritual, psychological and social dimensions of quality of life in breast cancer woman receiving chemotherapy (Persian)]', Nursing Research, vol.3, no.2, pp.5565.

Ali Akbari F, Khalifehzadeh A, Parvin, A 2009, 'The effect of short time telephone follow-up on physical conditions and quality of life in patients after pacemaker implantation (Persian)], Shahrekord University of Medical Sciences Journal, vol.11, no.3, pp.23-8.

Allen-Davis, JT, Beck, A, Parker, R, Ellis, JL \& Polley, D 2002, 'Assessment of vulvovaginal complains: accuracy of telephone triage and in- office diagnosis', Obstetrics and Gynecol$o g y$, vol.99, no.1, pp.18-22.
Azar, M \& Gabbay, R 2009, 'Web-based management of diabetes through glucose uploads: has the time come for telemedicine?', Diabetes Research Clinical Practice, vol.8, no.3, pp.9-17.

Beaver, K, Wilson, C, Procter, D, Sheridan, J, Towers, G, Health J et al. 2011, 'Colorectal cancer follow-up: patient satisfaction and amenability to telephone after care', European Journal of Oncology Nursing, vol.15, no.1, pp.23-30. doi: 10.1016/j. ejon.2010.05.006

Beaver, K, Bogg, J \& Luker, K 1999, 'Decision-making role preferences and information needs: a comparison of colorectal and breast cancer', Health Expectations, vol.2, no.4, pp.266-76.

Beaver, K, Williamson, S \& Chalmers, K 2010, 'Telephone followup after treatment for breast cancer: views and experiences of patients and specialist breast care nurses', Journal of Clinical Nursing, vol.19, no.(19-20), pp.2916-24. doi: 10.1111/j.13652702.2010.03197.x.

Black, PK 2005, 'Psychological, sexual, and cultural issues for patients with the stoma', British Journal of Nursing, vol.13, no.12, pp.692-5. doi: 10.12968/bjon.2004.13.12.13254

Braun, E, Baidusi A, Alroy, G, Azzem, ZS, Braun, E, Baidusi et al. 2009, 'Telephone follow-up improves patients satisfaction following hospital discharge', European Journal of Internal Medicine, vol.20, no.2, pp.221-5. doi: 10.1016/j.ejim.2008.07.021

Burch, J 2005, 'Caring for peristomal skin: What every nurse should know', British Journal of Nursing, vol.19, no.3, pp.16672. doi: 10.12968/bjon.2010.19.3.46538

Care of Ostomy. 2007 [7 Oct 2007]. Available from: www.hbd.ir

Charua-Guindic, L, Benavides-Leon, CJ, Vhllanueva-Herreo, JA Jimenez-Bobadilla, B, Abdo-Francis, JM \& Herandez-Labra, E 2011, 'Quality of life in ostomized patient', Cirugía y Cirujanos journal, vol.79, no.2, pp.136-41. PMID:21631976

Cinar, FI, Akbayrak, N, Cinar, M, Karadurmus, N, Sahin, M, Dogru, T, Sonmez, A, Tosun, N \& Kilic, S 2010, 'The effectiveness of nurse-led telephone follow-up in patients with type 2 diabetes mellitus', Turkish Journal of Endocrinology and Metabolism, no.14, pp.1-5. doi: 10.1007/s00384-002-0462-z

Duchesne, JC, Wang, YZ, Weintraub, SL \& Boyle, S 2002, 'Stoma complications: a multivariate analysis', The American Journal of Surgery, vol.68, no.11, pp.961-6. PMID:12455788

Grinspun, D 2009, Ostomy care and management: Clinical best practice guidelines, Registered Nurses' Association Of Ontario Pub, Toronto.

Holst, M, Willenheimer, R, Martensson, J, Lindholm, M \& Stromberg, A 2007, 'Telephone follow-up of self-care behaviour after a single session education of patients with heart failure in primary health care', European Journal of Cardiovascular Nursing, vol.6, no.2, pp.153-62. doi: 10.1016/j.apnr.2016.03.005

International Nurses Concil. 2006. Available from: http:// www.icn.ch.

Iranian Ostomy Society 2012, 'About the Iranian Ostomy Society [Internet]', viewed 2 June 2012, http:/ / www.iranostomy. com/index.php

Karadag, A, Mentes, BB, Uner, A, Irkorucu, O \& Ayaz S 2003, 'Impact of stomatherapy on quality of life in patients with permanent colostomies or ileostomies', International Journal of 
Colorectal Disease, vol.18, no.3, pp.234-8. doi: 10.1111/j.13652702.2010.03197.x

Kimman, ML, Dirksen, CD, Voogd, AC, Falger, P, Gijsen, BC, Thuring, M et al. 2011, 'Nurse-led telephone follow-up and an educational group programme after breast cancer treatment: results of a $2 \times 2$ randomised controlled trial', European Journal of Cancer, vol.47, no.7, pp.1027-63. doi: 10.1016/j.ejcnurse.2006.06.006

Krouse, R, Grant, M, Ferrell, B, Dean, G, Nelson, R \& Chu, D 2007, 'Quality of life outcomes in 599 cancer and 599 noncancer patients with colostomies', Journal of Surgical Research, vol.138, no.1, pp.79-87. doi: 10.1016/j.jss.2006.04.033

Liu, JE, Mok, E, Wong, T 2005, 'Perceptions of supportive communication in Chinese patients with cancer: experiences and expectations', Journal of Advanced Nursing, vol.52, no.3, pp.26270.

Mistiaen, P \& Poot, E 2006, 'Telephone follow-up, initiated by a hospital-based health professional, for post discharge problems in patients discharged from hospital to home (review)', Cochrane Database of Systematic Reviews, vol.18, no.4, pp.CD004510. doi: 10.1002/14651858.CD004510.pub3

Nobahar, M 2002, '[Nursing in digestive tract cancer and stomas (Persian)]', Boshra Pub, Tehran.

Ontario, R 2009, 'Ostomy care and management: Clinical best practice guidelines', Registered Nurses's Association of Ontari Pub, Toronto.

Peck, A 2005, 'Changing the fact of standard nursing practice through telehealth and telenursing', Nursing Administration Quarterly, vol.29, no.4, pp.339-43.

Persson, E, Severinsson, E \& Hellstrom, AL 2004, 'Spouses' perceptions of and reactions to living with a partner who has undergone surgery for rectal cancer resulting in a stoma', Journal of Cancer Nursing, vol.27, no.1, pp.85-90. doi:10.1097/ WON.0b013e3181a39347

Pisani, P, Bray, F \& Parkin, DM 2002, 'Estimates of the worldwide prevalence of cancer for 25 sites in the adult population. International Journal of Cancer, vol.97, no.1, pp.72-81.

Pittman, J, Kozell, K \& Gray, M 2009, 'Should woc nurses measure health-related quality of life in patients undergoing intestinal ostomy surgery?', Journal of Wound Ostomy E Continence Nursing, vol.35, no.5, pp.493-503. doi: 10.12968/ bjon.2001.10.19.10000

Pringle, W, Swan, E 2001, 'Continuing care after discharge from hospital for stoma patients', British Journal of Nursing, vol.10, no.19, pp.1275-88. doi: 10.12968/bjon.2001.10.19.10000

Ralston, JD, Hirsch, IB, Hoath, J, Mullen, M, Cheadle, A \& Goldberg, HI 2009, 'Web-based collaborative care for type 2 diabetes: a pilot randomized trial. Diabetes Care, vol.32, no.2, pp.234-9.

Richbourg, L, Thorpe, JM \& Rapp, CG 2007, 'Difficulties experienced by the ostomates after hospital discharge', Journal of Wound, Ostomy \& Continence Nursing, vol.34, no.1, pp.70-9. doi: 10.1016/j.ejca.2010.12.003

Sacco, WP, Morrison, AD, Malon, JI 2004, 'A brief, regular, proactive telephone "coaching" intervention for diabetes rational, description, and preliminary results. Journal of Dia- betes Complications, vol.18, no.2, pp.113-8. doi: 10.1016/S10568727(02)00254-4

Sadeghi, T, Shahabinejhad, M, Derakhshan, R, Balaii, P 2010, '[Effect of nurse-led telephone follow up (telenursing) on hba1c among diabetic patients (Persian)]', Journal of Rafsanjan University of Medical Sciences, vol.9, no.3, pp.175-84.

Sammarco, A 2001, 'Psychosocial stages and quality of life of women with breast cancer', Journal of Cancer Nursing, vol.24, no.4, pp.272-9. doi: 10.1111/j.1365-2648.2005.03583.x

Smith, DM, Loewenstein, G, Rozin, P, Sherriff, RL \& Ubel, PA 2007, 'Sensitivity to disgust, stigma, and adjustment to life with a colostomy', Journal of Research in Personality, vol.41, no.4, pp.787-803. doi:10.1016/j.jrp.2006.09.006

Williams, J 2007, 'Stoma care nursing: what the community nurse needs to know', British Journal of Community Nursing, vol.12, no.8, pp.342-6. doi: 10.12968/bjcn.2007.12.8.24361

Wu, HK, Chau, JP \& Twinn, S 2007, 'Self- efficacy and quality of life among stoma patients in Hong Kong', Cancer Nursing vol.30, no.31, pp.186-93.

Xu, HL 2009, 'A review of stoma care and enterostomal therapist', Shanghai Nursing, no.3, pp.93-5. PMID: 17228210

Yang, FY, Liu, LH \& Chen, YF 2003, 'Survey of nursing care needs for cancer patients after discharge', Chinese Tomor no.12, pp.269-271. PMID:15108956

Zakerimoghadam, M, Bassampour, S, Rajab, A, Faghihzadeh, S \& Nesari, M 2008, '[Effect of nurse-led telephone follow ups (tele-nursing) on diet adherence among type 2 diabetic patients (Persian)], The Journal of Faculty of Nursing \& Midwifery, vol.14, no.2, pp.63-71.

Zhang, JE, Wong, FK, You, LM \& Zheng, MC 2012, 'A qualitative study exploring the nurse telephone follow-up of patients returning home with a colostomy', Journal of Clinical Nursing, vol.21, no.9-10, pp.1407-15. doi: 10.1111/j.13652702.2011.03824.x

Zheng, MC, Zhang, JE, Qin, YJ, Fang, YJ \& Wu, XJ 2013, 'Telephone follow-up for patients returning home with colostomies: views and experiences of patients and enterostomal nurses', European Journal of Oncology Nursing, vol.17, no.2, pp.184-9. doi: 10.1016/j.ejon.2012.05.006 